\title{
Breastfeeding and Its Associated Risk in Children with Acute Leukemia: A Retrospective Study
}

\begin{abstract}
Aim: This study aims to study the protective risk association between the breastfeeding pattern and acute leukemia in children. Materials and Methods: Retrospective study in Kidwai Institute of Oncology, Bangalore. One hundred and twenty cases and 120 controls were enrolled during April 1, 2015-July 31, 2015. Cases include children diagnosed with acute leukemia either ALL or AML, between the age group of 1-15 years, with an elderly sibling and availability of biologic mother for collecting data regarding breastfeeding pattern. Controls include the elder sibling of the cases, children on compassionate care toward end of life, and also whose mother denied to give consent were excluded from the study. Statistical Analysis Used: Pearson Chi-square test, conditional logistic regression models, and Fischer's extract tests were used to assess the association between breastfeeding patterns and risk of acute leukemia. Results: The acute leukemia cases and controls were similar with respect to sex, birthweight, maternal education, and socioeconomic status. Frequency of ever breastfeeding was same $99 \%$ in both cases and controls, odds ratio of ever breastfed to never breastfed (odds ratio $=1 ; 95 \%$ confidence interval $=0.13-7.21$ ) was not associated with risk of acute leukemia. Exclusive breastfeeding $\leq 2,2-4$ and 4-6 months as compared to exclusive breastfeeding beyond 6 months were associated with significant risk of acute leukemia and the $P$ value trend is 0.0026 . Similarly, continued breastfeeding till 1 year of age as compared to beyond 1 year was also associated with highly significant risk of acute leukemia with $P$ value trend of 0.0001 . Whereas continued breastfeeding till 2 years as compared to beyond 2 years was not associated with any risk of acute leukemia with $P$ value trend of 0.3433 . Conclusion: Significant association between breastfeeding and risk of acute leukemia was observed.

Keywords: Acute leukemia, breastfeeding, children
\end{abstract}

\section{Introduction}

Leukemia accounts for about $31 \%$ of all malignancies occurring in children. ${ }^{[1]}$ Infection was the first suggested causal exposure for childhood acute leukemia and still remains to be the strongest risk factor. ${ }^{[2]}$ Greaves hypothesis states that common B-cell precursor acute lymphoblastic leukemia arises as consequence of abnormal response to common infections in two genetic events. $^{[3]}$ Maternal breastfeeding may protect against childhood leukemia by modulating the child's immune system early in life to respond effectively during exposure to common infections. Since there is paucity of literature, there is a need to analyze the patterns of maternal breastfeeding among children with acute leukemia.

This is an open access journal, and articles are distributed under the terms of the Creative Commons Attribution-Non Commercial-ShareAlike 4.0 License, which allows others to remix, tweak, and build upon the work non-commercially, as long as appropriate credit is given and the new creations are licensed under the identical terms.

For reprints contact: reprints@medknow.com

\section{Materials and Methods}

A case-control study was conducted among 120 children admitted with acute leukemia between the age group of 1-15 years during the period of March-July 2015. Cases include children diagnosed with acute leukemia either ALL or AML, between the age group of 1-15 years of age, with an elderly sibling, and availability of biologic mother for collecting data regarding breastfeeding pattern. Controls were the elder sibling of the cases to reduce the major confounding factors.

\section{Data collection}

Information regarding maternal exposures, both preconception and prenatal exposures, was collected along with information regarding breastfeeding and feeding characteristics through interview of mothers of study individuals with the use of a structured questionnaire. Respondents

\footnotetext{
How to cite this article: Lingappa AL, Kalapalar SR, Rudrappa SR, Manjunatha SN. Breastfeeding and its associated risk in children with acute leukemia: A retrospective study. Indian J Med Paediatr Oncol 2018;39:312-5.
}

\section{Appaji L Lingappa, Suresh R Kalapalar ${ }^{1}$, Sudha R Rudrappa ${ }^{2}$, SN Manjunatha ${ }^{3}$}

Department of Pediatric Oncology, Kidwai Memorial Institute, Bengaluru,

Departments of ${ }^{2}$ Pediatrics and ${ }^{3}$ Community Medicine, Mysore Medical College and Research Institute, Mysore, Karnataka, ${ }^{1}$ Department of Pediatrics, SRM Medical College and Research Institute, Chennai, Tamil Nadu, India
Address for correspondence: Dr. Suresh R Kalapalar, Department of Pediatrics, SRM Medical College and Research Institute, Potheri, Chennai, Tamil Nadu, India. E-mail:surmbbs@gmail.com

Access this article online Website: www.ijmpo.org DOI: 10.4103/ijmpo.ijmpo_18_17 Quick Response Code:

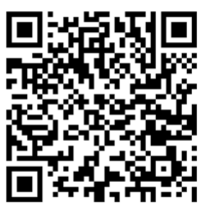


were asked questions regarding the feeding characteristics. Breastfeeding was analyzed as a binary (ever/never) variable. Duration of breastfeeding was analyzed as reported (continuous) in months and as categories of none, $\leq 2,3-4,5-6,7-12,13-18,19-24$ months, and $>2$ years. Exclusive breastfeeding (in relation to consuming other milk or formula) was derived from duration of breastfeeding (continuous) and the age when the child was first introduced to formula or milk (categorical) and was categorized as formula only, breast milk only for $\leq 2,3-4$, $5-6,7-12,13-18,19-24$ months, and $>2$ years.

\section{Statistical analysis}

The analysis of breastfeeding characteristics and risk of childhood leukemia was made. Baseline characteristics of cases and controls were compared with the Pearson Chi-square test. To assess the association between breastfeeding and other early feeding patterns and risk of acute leukemia, conditional logistic regression models and Fischer's extract tests were used. Odds ratios (ORs) were considered to be consistent with statistical significance if their $95 \%$ confidence intervals (CIs) excluded 1.00. Stratified analyses were conducted to evaluate the potential confounding and modifying effects of selected sociodemographic characteristics and postulated risk factors. Confounding effects were further examined in the conditional logistic regression analyses by comparing the OR of breastfeeding with and without adjustment for confounding factor(s). A confounding effect was defined if a $10 \%$ difference in the unadjusted and adjusted ORs were observed. $P>0.05$ is considered significant for additive models; analyses were carried out for all acute leukemias combined.

\section{Results}

The acute leukemia cases and controls were similar with respect to sex, birthweight, maternal education, and socioeconomic status [Table 1]. Frequency of ever breastfeeding was same $99 \%$ in both cases and the controls, odds ratio of ever breastfed as compared to never breastfed $(\mathrm{OR}=1 ; 95 \% \mathrm{CI}=0.13-7.21)$ was not associated with risk of acute leukemia [Table 2]. Exclusive breastfeeding $\leq 2,2-4$, and 4-6 months as compared to exclusive breastfeeding beyond 6 months were associated with significant risk of acute leukemia and the $P$ value trend is 0.0026 calculated using Fischer's exact test. Similarly, continued breastfeeding till 1 year of age as compared to beyond 1 year was also associated with highly significant risk of acute leukemia with $P$ value trend of 0.0001 [Table 2]. Whereas continued breastfeeding till 2 years as compared to beyond 2 years was not associated with any risk of acute leukemia with $P$ value trend of 0.3433 .

\section{Discussion}

The present study investigated the effect of breastfeeding and other early childhood feeding practices in relation to the risk of childhood acute leukemia. Breastfeeding for at

\begin{tabular}{lccc}
\hline \multicolumn{3}{c}{ Table 1: Demographic, maternal and birth related } \\
characteristics \\
Parameters & $\begin{array}{c}\text { Cases, } \\
\boldsymbol{n}(\%)\end{array}$ & $\begin{array}{c}\text { Controls, } \\
\boldsymbol{n}(\mathbf{\%})\end{array}$ & $\boldsymbol{P}^{\mathbf{a}}$ \\
\hline Mean age (years) & $2.8 \pm 0.50$ & $5.1 \pm 0.72$ & \\
Child sex & $76(63)$ & $68(57)$ & \\
Male & $44(37)$ & $52(43)$ & \\
Female & & & \\
Birth weight (g) & $11(9)$ & $12(10)$ & 0.1205 \\
$<2500$ & $49(40)$ & $44(37)$ & \\
$2500-2999$ & $33(28)$ & $40(33)$ & \\
$3000-3499$ & $5(4)$ & $4(3)$ & \\
$>3500$ & $22(19)$ & $20(17)$ & \\
Unknown & $2.899 \pm 0.483$ & $2.991 \pm 0.335$ & \\
Mean (g) \pm SD & & & \\
Maternal education & $75(62)$ & $75(62)$ & 1.000 \\
$\leq$ High school & $39(33)$ & $39(33)$ & \\
Posthigh school & $6(5)$ & $6(5)$ & \\
College graduate & & & \\
Socioeconomic status (as per & & & \\
modified Kuppuswamy scale) & & $3(2)$ & 1.0000 \\
Class I & $3(2)$ & $11(10)$ & \\
Class II & $11(10)$ & $17(14)$ & \\
Class III & $17(14)$ & $84(70)$ & \\
Class IV & $84(70)$ & $5(4)$ & \\
Class V & $5(4)$ & 120 & \\
Total & 120 & & \\
\hline
\end{tabular}

aPearson test; two-sided. SD - Standard deviation

least 6 months was associated with reduced risk of acute leukemia among children diagnosed between age 1 and 14 years of age. Exclusive breastfeeding beyond 6 months showed a statistically significant reduced risk of childhood acute leukemia and also continued breastfeeding along with complementary feeds for at least 1 year was found to be highly significant in reducing the risk of childhood acute leukemia. Petridou et al., 1997:;4] Shu et al., 1999; ${ }^{[5]}$ Smulevich et al., 1999; $;{ }^{[6]}$ Infante-Rivard et al., 2000; ${ }^{[7]}$ Bener et al., 2001; ${ }^{[8]}$ and Perrillat et al., 2002; ${ }^{[9,10]}$ have reported a statistically significant protective association between breastfeeding and risk of childhood leukemia. Among these, only one study described a borderline statistical significance of breastfeeding on risk of acute leukemia among children diagnosed $<4$ years of age. In contrast, seven case-control studies such as by Dockerty et al., 1997; $;^{[1]}$ McKinney et al., 1999:;12] Schüz et al., 1999:;113] Rosenbaum et al., 2000:;14] Hardell and Dreifaldt, 2001; $;^{[15]}$ Lancashire and Sorahan, 2003; ${ }^{[16]}$ and Jourdan-Da Silva et al., 2004 ${ }^{[17]}$ have reported no association between breastfeeding and overall childhood leukemia. Control selection strategies in all of these breastfeeding studies included the use of population-based (11 studies), hospital-based (five studies), and random digit dial (two studies) controls with sample sizes varying from a low of 63 cases of all leukemia ${ }^{[18]}$ to a high of 2200 cases of all leukemia. ${ }^{[5]}$ In the previous studies, controls were taken comparing data on parental 


\begin{tabular}{|c|c|c|c|c|}
\hline Parameters & Cases $(n)$ & Controls $(n)$ & Adjusted OR (95\% CI) ${ }^{\mathrm{a}}$ & $P^{\mathbf{b}}$ \\
\hline \multicolumn{5}{|l|}{ Breastfeeding initiation } \\
\hline Never & 1 & 1 & & \\
\hline Ever & 119 & 119 & $1(0.13-7.21)$ & \\
\hline \multicolumn{5}{|l|}{ Exclusive breastfeeding } \\
\hline Formula only & 1 & 1 & & 0.0026 \\
\hline$<2$ months breast milk only & 5 & 2 & $2.57(0.49-13.49)$ & \\
\hline 2-4 months breast milk only & 15 & 9 & $1.76(0.74-4.2)$ & \\
\hline 4-6 months breast milk only & 44 & 29 & $1.82(1.04-3.18)$ & \\
\hline 6-12 months breast milk only & 45 & 70 & $0.43(0.26-0.72)$ & \\
\hline$>1$ year breast milk only & 10 & 9 & $1.12(0.44-2.87)$ & \\
\hline \multicolumn{5}{|l|}{ Continued breastfeeding } \\
\hline$<2$ months breast milk & 5 & 1 & $5.18(0.6-44.99)$ & \\
\hline 2-4 months breast milk & 0 & 0 & & \\
\hline 4-6 months breast milk & 8 & 3 & $2.79(0.72-10.77)$ & \\
\hline 6-9 months breast milk & 5 & 1 & $5.18(0.6-44.99)$ & \\
\hline 9-12 months breast milk & 25 & 3 & $10.28(3.01-35.11)$ & 0.0001 \\
\hline 13-18 months breast milk & 25 & 32 & $0.72(0.4-1.32)$ & \\
\hline 19-24 months breast milk & 29 & 50 & $0.44(0.26-0.77)$ & \\
\hline$>2$ years months breast milk & 22 & 29 & $0.7(0.38-1.31)$ & 0.3433 \\
\hline
\end{tabular}

${ }^{\mathrm{a}} \mathrm{OR}$ - Odds ratio; CI - Confidence interval. OR and CI derived from conditional logistic regression; ${ }^{\mathrm{b}}$ Derived using the categorical variables in the Fischer's extract test

age, parental education, mother's reproductive history, and birthweight. In the present study, elderly siblings were taken as controls to match the parental education, socioeconomic status, and the region of residence.

The biological mother was asked whether she breastfed or not and how many months she only breastfed, thus allowing the calculation of an exclusive breastfeeding variable for analysis. She was also asked what type of formula or milk her child drank at or before 6 months and after 6 months of age. This current analysis examined breastfeeding and its pattern, thus providing a complete assessment of the potential associations between breast milk exposures and childhood leukemia risk.

\section{Conclusion}

This investigation was a comprehensive examination of breastfeeding patterns and the risk of childhood acute leukemia in an essentially hospital-based case-control study. Significant association between breastfeeding and risk of acute leukemia was observed. Overall, this study supports the hypothesis that breastfeeding protects against the risk of childhood acute leukemia.

\section{Financial support and sponsorship}

Nil.

\section{Conflicts of interest}

There are no conflicts of interest.

\section{References}

1. Tubergen DG, Bleyer A, Ritchey AK. The leukemias. In: Behrman RE, Kleigman RM, Jenson HB, editors. Nelson
Textbook of Pediatrics. 19 ${ }^{\text {th }}$ ed., Ch. 489. Pennsylvania: Elsevier Saunders; 2011. p. 1732-9.

2. Ward G. The infective theory of acute leukaemia. Br J Child Dis 1917; 14:10-20.

3. Greaves MF, Wiemels J. Origins of chromosome translocations in childhood leukaemia. Nat Rev Cancer 2003;3:639-49.

4. Petridou E, Trichopoulos D, Kalapothaki V, Pourtsidis A, Kogevinas M, Kalmanti M, et al. The risk profile of childhood leukaemia in Greece: A nationwide case-control study. Br J Cancer 1997;76:1241-7.

5. Shu XO, Linet MS, Steinbuch M, Wen WQ, Buckley JD, Neglia JP, et al. Breast-feeding and risk of childhood acute leukemia. J Natl Cancer Inst 1999;91:1765-72.

6. Smulevich VB, Solionova LG, Belyakova SV. Parental occupation and other factors and cancer risk in children: I. Study methodology and non-occupational factors. Int J Cancer 1999;83:712-7.

7. Infante-Rivard C, Fortier I, Olson E. Markers of infection, breast-feeding and childhood acute lymphoblastic leukaemia. $\mathrm{Br}$ J Cancer 2000;83:1559-64.

8. Bener A, Denic S, Galadari S. Longer breast-feeding and protection against childhood leukaemia and lymphomas. Eur J Cancer 2001;37:234-8.

9. Perrillat F, Clavel J, Auclerc MF, Baruchel A, Leverger G, Nelken B, et al. Day-care, early common infections and childhood acute leukaemia: A Multicentre French Case-Control Study. Br J Cancer 2002;86:1064-9.

10. Perrillat F, Clavel J, Jaussent I, Baruchel A, Leverger G, Nelken B, et al. Breast-feeding, fetal loss and childhood acute leukaemia. Eur J Pediatr 2002;161:235-7.

11. Dockerty JD, Skegg DC, Elwood JM, Herbison GP, Becroft DM, Lewis ME, et al. Infections, vaccinations, and the risk of childhood leukaemia. Br J Cancer 1999;80:1483-9.

12. McKinney PA, Juszczak E, Findlay E, Smith K, Thomson CS. Pre- and perinatal risk factors for childhood leukaemia and other malignancies: A Scottish case control study. Br J Cancer 
1999;80:1844-51.

13. Schüz J, Kaletsch U, Meinert R, Kaatsch P, Michaelis J. Association of childhood leukaemia with factors related to the immune system. Br J Cancer 1999;80:585-90.

14. Rosenbaum PF, Buck GM, Brecher ML. Early child-care and preschool experiences and the risk of childhood acute lymphoblastic leukemia. Am J Epidemiol 2000;152:1136-44.

15. Hardell L, Dreifaldt AC. Breast-feeding duration and the risk of malignant diseases in childhood in Sweden. Eur J Clin Nutr
2001;55:179-85.

16. Lancashire RJ, Sorahan T; OSCC. Breastfeeding and childhood cancer risks: OSCC data. Br J Cancer 2003;88:1035-7.

17. Jourdan-Da Silva N, Perel Y, Méchinaud F, Plouvier E, Gandemer V, Lutz P, et al. Infectious diseases in the first year of life, perinatal characteristics and childhood acute leukaemia. Br J Cancer 2004;90:139-45.

18. Davis MK, Savitz DA, Graubard BI. Infant feeding and childhood cancer. Lancet 1988;2:365-8. 